\title{
Consumo e desempenho de ovinos alimentados com silagens de cana-de-açúcar tratadas com óxido de cálcio e cloreto de sódio
}

\author{
[Intake and performance of lambs fed with sugarcane silages treated with \\ whitewash and sodium chloride] \\ F.H.S. Rabelo ${ }^{1}$, A.V. Rezende ${ }^{1}$, C.H.S. Rabelo ${ }^{2}$, D.A. Nogueira ${ }^{3}$, W.A. Silva ${ }^{1}$, \\ P.F. Vieira ${ }^{1}$, W.B. Santos ${ }^{1}$ \\ ${ }^{1}$ Universidade José do Rosário Vellano - Unifenas - Alfenas, MG \\ ${ }^{2}$ Universidade Estadual Paulista - Unesp - Jaboticabal, SP \\ ${ }^{3}$ Universidade Federal de Alfenas - Unifal - Alfenas, MG

\section{RESUMO}

Avaliaram-se o consumo e o desempenho de ovinos alimentados com silagens de cana-de-açúcar tratadas com óxido de cálcio $(\mathrm{CaO})$ e cloreto de sódio $(\mathrm{NaCl})$. Utilizaram-se sete tratamentos: controle (silagem sem aditivo), silagens com 0,$5 ; 1,0$ e $1,5 \%$ de $\mathrm{CaO}$ e silagens com 0,$5 ; 1,0$ e 2,0\% de $\mathrm{NaCl}$, com quatro repetições. Os animais consumiram maior quantidade de matéria seca e de nutrientes digestíveis totais quando se adicionou $0,5 \%$ de $\mathrm{NaCl}$ ou ainda 1,0 e 1,5\% de $\mathrm{CaO}$. Quanto à fibra em detergente neutro e à proteína bruta, observou-se maior consumo quando se adicionou $0,5 \%$ de $\mathrm{NaCl}$ ou $1,0 \%$ de $\mathrm{CaO}$. Não foi observado efeito da dieta sobre o ganho médio diário de peso. A adição de $0,5 \%$ de cloreto de sódio e $1,0 \%$ de óxido de cálcio à silagem de cana-de-açúcar resultou em aumento no consumo e melhora no desempenho de ovinos.

Palavras-chave: ovino, aditivo químico, nutrição, Saccharum officinarum

\begin{abstract}
The intake and performance of lambs fed with sugarcane silages treated with whitewash and chloride sodium were evaluated. Seven treatments were used: untreated silage (control); silages treated with 0.5; 1.0 and $1.5 \%$ of $\mathrm{CaO}$ (whitewash); and silages treated with 0.5; 1.0 and $2.0 \%$ of $\mathrm{NaCl}$, with four replicates per treatment. The animals were fed a higher amount of dry matter and total digestible nutrients when the sugarcane silages were treated with $0.5 \%$ of $\mathrm{NaCl}, 1.0$ and $1.5 \%$ of $\mathrm{CaO}$. The intake of neutral detergent fiber and crude protein increased when the lambs were fed silages treated with $0.5 \%$ of $\mathrm{NaCl}$ and $1.0 \%$ of $\mathrm{CaO}$. The average daily gain did not differ among treatments. The inclusion of $0.5 \%$ of sodium chloride and $1.0 \%$ of whitewash in sugarcane silages increased the intake and improved the performance of lambs.
\end{abstract}

Keywords: lams, chemical additive, nutrition, Saccharum officinarum

\section{INTRODUÇÃO}

Sabe-se que a alimentação de ruminantes, no Brasil, é predominantemente baseada em forragens, as quais são escassas em certos períodos do ano, ocasionando baixos índices de produtividade (Bolzan et al., 2007). Nesse contexto, a cana-de-açúcar tem se apresentado como alternativa economicamente viável,

Recebido em 31 de outubro de 2011

Aceito em 26 de novembro de 2012

E-mail: flaviohsr.agro@yahoo.com.br gerando coeficientes de desempenho animal satisfatórios quando comparada com qualquer outra fonte de alimento volumoso (Magalhães $e t$ al., 2004; Santos et al., 2008; Nussio et al., 2009). Entretanto, essa cultura demanda mão de obra diária para cortes, despalha, transporte e picagem e determina restrições operacionais quando se pretende suplementar os animais (Lopes e Evangelista, 2010), o que pode ser contornado pelo uso da técnica de ensilagem (Balieiro Neto et al., 2007). 
Todavia, no processo de ensilagem da cana-deaçúcar, recomenda-se utilizar algum aditivo químico ou bacteriano que favoreça a fermentação, com o objetivo de reduzir as perdas totais e melhorar o valor nutritivo da silagem obtida (Torres et al., 2003; Balieiro Neto et al., 2007) e, assim, alcançar resultados bastante variáveis (Freitas et al., 2006). Entre os aditivos mais utilizados para esse fim, encontra-se a cal virgem (óxido de cálcio - $\mathrm{CaO}$ ), a qual pode reduzir os constituintes da parede celular por hidrólise alcalina e contribuir para a preservação de nutrientes solúveis por inibir o desenvolvimento de leveduras que atuam sobre a massa ensilada, amenizando a perda de nutrientes durante a ensilagem e após a abertura do silo (Balieiro Neto et al., 2007; Amaral et al., 2009). Balieiro Neto et al. (2009) observaram que ovinos alimentados com cana-de-açúcar in natura e silagem de cana-de-açúcar acrescida de cal virgem apresentaram consumo de matéria seca semelhante, sendo esses resultados superiores ao observado com utilização de aditivo microbiano (Lactobacillus buchneri).

Outro aditivo com grande potencial para utilização no processo de ensilagem é o cloreto de sódio $(\mathrm{NaCl})$, pois ele atua sobre a atividade de microrganismos do alimento, o que causa alterações de $\mathrm{pH}$ e redução da atividade da água, possibilitando a manipulação do processo fermentativo e o aumento na estabilidade da silagem após abertura dos silos (Rezende et al., 2011). A ação osmótica que o sal exerce pode resultar em redução dos valores de $\mathrm{pH}$, assim como no decréscimo da atividade de água do meio (Woolford, 1978), além do que muitas bactérias ácido-lácticas sobrevivem em determinadas concentrações de sal (Gava, 1984), as quais são desejáveis para a produção do ácido láctico.

No entanto, o uso do $\mathrm{NaCl}$ em dosagens inadequadas pode ter efeito direto sobre a aceitabilidade dos alimentos, o que afeta diretamente o consumo e o desempenho animal. $\mathrm{E}$, nesse contexto, não há trabalhos que avaliem o efeito da inclusão de $\mathrm{NaCl}$ no processo de ensilagem sobre a resposta animal. Portanto, objetivou-se avaliar o consumo e o desempenho de ovinos alimentados com silagens de cana-deaçúcar tratadas com óxido de cálcio e cloreto de sódio.

\section{MATERIAL E MÉTODOS}

Para confecção das silagens, foi utilizada a canade-açúcar cultivar SP81-3250 (grau brix $=19^{\circ}$ ), com 24 meses de rebrota. A cana-de-açúcar foi desintegrada em picadeira estacionária em partículas com tamanho próximo a $2,0 \mathrm{~cm}$. A forragem picada recebeu a adição de 0,$5 ; 1,0$ e 1,5\% de $\mathrm{CaO} ; 0,5 ; 1,0$ e 2,0\% de $\mathrm{NaCl}$, com base na massa verde. Para servir de comparação, a forragem também permaneceu sem adição de aditivos (silagem controle). $\mathrm{O} \mathrm{NaCl}$ foi misturado à cana-de-açúcar em forma de sal comum, e o $\mathrm{CaO}$ em forma de pó micropulverizado (cal virgem), de tal forma que a massa triturada ficasse o menor tempo possível em exposição ao ar. A cal virgem apresentou teor de matéria seca (MS) e de óxido de cálcio de $99 \%$ e $64 \%$, respectivamente.

Como silos experimentais, foram utilizados tambores cilíndricos de polietileno (capacidade para $130,0 \mathrm{~kg}$ ) para o acondicionamento das massas. A compactação foi realizada por meio de pisoteio humano e os silos foram vedados com lona plástica, presa por gomas de borracha, permanecendo fechados por 60 dias. Após a abertura deles, as silagens foram ofertadas aos animais com o concentrado (composto por milho triturado e farelo de soja) e de forma individual, em duas refeições diárias ad libitum, às sete e às 16 horas (Tab. 1 e 2). A quantidade de alimento ofertada durante o período de adaptação dos animais foi ajustada de modo a manter as sobras em aproximadamente $10 \%$ do total oferecido, com água e sal mineral permanentemente à disposição dos animais.

$\mathrm{Na}$ avaliação do consumo, utilizaram-se 14 ovelhas sem raça definida, com peso vivo médio de $22,4 \mathrm{~kg} \pm 1,8 \mathrm{~kg}$, alojadas em gaiolas individuais para estudo metabólico, providas de comedouro, bebedouro e cocho para suplementação mineral. Os animais foram distribuídos em blocos ao acaso, em duas fases experimentais, avaliando-se as sete silagens como base das dietas experimentais, com quatro repetições, sendo que cada animal correspondeu a uma parcela. O experimento foi desenvolvido em dois períodos consecutivos e imediatos de 15 dias, sendo 10 dias de adaptação à dieta e ao ajuste do consumo e cinco dias para coleta de dados. 
Tabela 1. Composição bromatológica (\% na MS) dos ingredientes utilizados na formulação do concentrado

\begin{tabular}{lcccc}
\multicolumn{1}{c}{ Concentrado $^{1}$} & MS & FDN & FDA & PB \\
\hline Milho triturado & 86,48 & 14,87 & 5,21 & 9,53 \\
Farelo de soja & 87,25 & 16,31 & 9,84 & 45,01 \\
\hline
\end{tabular}

${ }^{1} \mathrm{MS}$ = matéria seca; FDN = fibra em detergente neutro; FDA = fibra em detergente ácido; PB = proteína bruta.

Tabela 2. Composição químico-bromatológica (\% na MS) das dietas experimentais

\begin{tabular}{|c|c|c|c|c|c|c|c|}
\hline \multirow{2}{*}{ Item $^{1}$} & \multicolumn{3}{|c|}{$\mathrm{NaCl}$} & \multirow{2}{*}{ Controle } & \multicolumn{3}{|c|}{$\mathrm{CaO}$} \\
\hline & $0,5 \%$ & $1,0 \%$ & $2,0 \%$ & & $0,5 \%$ & $1,0 \%$ & $1,5 \%$ \\
\hline MS & 27,21 & 26,21 & 27,31 & 25,29 & 32,18 & 33,41 & 33,14 \\
\hline $\mathrm{pH}$ & 3,53 & 3,53 & 3,59 & 3,53 & 3,77 & 3,86 & 4,00 \\
\hline FDN & 53,28 & 56,43 & 55,86 & 58,74 & 53,50 & 57,57 & 48,78 \\
\hline FDA & 22,75 & 24,87 & 23,55 & 20,35 & 21,54 & 17,36 & 14,60 \\
\hline Hemicelulose & 30,52 & 31,55 & 32,31 & 38,39 & 31,96 & 40,21 & 34,18 \\
\hline $\mathrm{PB}$ & 3,34 & 3,27 & 3,46 & 4,44 & 2,52 & 2,80 & 2,34 \\
\hline DMS (\%) & 71,17 & 69,52 & 70,55 & 73,04 & 72,12 & 75,37 & 77,52 \\
\hline NDT (\%) & 71,91 & 70,42 & 71,35 & 73,59 & 72,76 & 75,68 & 77,62 \\
\hline ED (Mcal/kg MS) & 3,16 & 3,10 & 3,14 & 3,24 & 3,20 & 3,33 & 3,42 \\
\hline EM (Mcal/kg MS) & 2,60 & 2,54 & 2,58 & 2,66 & 2,63 & 2,73 & 2,80 \\
\hline
\end{tabular}

${ }^{1} \mathrm{MS}$ = matéria seca; FDN = fibra em detergente neutro; FDA = fibra em detergente ácido; $\mathrm{PB}=$ proteína bruta; DMS = digestibilidade aparente da matéria seca; NDT = nutrientes digestíveis totais; $\mathrm{ED}$ = energia digestível; $\mathrm{EM}=$ energia metabolizável.

O consumo voluntário de matéria verde (MV), matéria seca (MS), fibra em detergente neutro (FDN), fibra em detergente ácido (FDA), hemicelulose (HEM), proteína bruta (PB), nutrientes digestíveis totais (NDT), energia digestível (ED) e energia metabolizável (EM) foi calculado pela diferença entre a quantidade ofertada e a quantidade recusada pelos animais (sobras). Além disso, os animais foram pesados a cada sete dias, sendo essas pesagens precedidas de jejum de sólidos por aproximadamente 14 horas, para avaliação do ganho de peso médio diário (GPMD) e total (GPMT).

As análises das silagens e dos ingredientes que compunham o concentrado foram realizadas utilizando-se o método convencional de secagem em estufa ventilada a $55^{\circ} \mathrm{C}$ por 72 horas, para, então, proceder-se à moagem em moinho tipo "Willye", com posterior determinação da MS a $105^{\circ} \mathrm{C}$ por 12 horas, obtendo-se o teor de MS total. Os teores de FDN, FDA, PB e HEM foram determinados segundo as metodologias descritas por Silva e Queiroz (2002), assim como a determinação do $\mathrm{pH}$. Os valores de NDT foram obtidos por meio da equação descrita por Cappelle et al. (2001): \%NDT = 91,6086 $(0,669233 * \% \mathrm{FDN})+(0,437932 * \% \mathrm{~PB}) . \mathrm{A}$ digestibilidade aparente da MS (DMS), ED e EM foi obtida por meio das equações descritas por Rodrigues (2009): \%DMS = 88,9 - $(0,779 *$ $\%$ FDA); ED Mcal $/ \mathrm{kg} / \mathrm{MS}=\%$ NDT * 0,04409; $\mathrm{EM} \mathrm{Mcal} / \mathrm{kg} / \mathrm{MS}=\mathrm{ED} * 0,82$, respectivamente.

Os resultados obtidos foram submetidos à análise de variância por meio do software SISVAR ${ }^{\circledR}$ (Ferreira, 2008), comparando-se as médias pelo teste de Scott-Knott a 5\% de significância.

\section{RESULTADOS E DISCUSSÃO}

Os animais consumiram maior quantidade de MV e MS em kg/dia $(\mathrm{P}<0,05)$ quando alimentados com silagens de cana-de-açúcar tratadas com $1,0 \%$ de $\mathrm{CaO}$ e $0,5 \%$ de $\mathrm{NaCl}$ (Tab. 3). Embora não tenham sido realizadas análises sobre o perfil fermentativo das silagens, esse resultado possivelmente pode estar associado à menor fermentação alcoólica obtida nesses tratamentos. Nussio e Schmidt (2005) constataram que o acúmulo de etanol pode não somente representar perdas do material ensilado, mas também perdas decorrentes da recusa dos animais. 
Tabela 3. Consumo de matéria seca e de nutrientes por ovinos alimentados com dietas à base de silagens de cana-de-açúcar tratadas quimicamente

\begin{tabular}{|c|c|c|c|c|c|c|c|c|}
\hline \multirow{2}{*}{ Item $^{1}$} & \multicolumn{3}{|c|}{$\mathrm{NaCl}$} & \multirow{2}{*}{ Controle } & \multicolumn{3}{|c|}{$\mathrm{CaO}$} & \multirow{2}{*}{$\mathrm{CV}(\%)$} \\
\hline & $0,5 \%$ & $1,0 \%$ & $2,0 \%$ & & $0,5 \%$ & $1,0 \%$ & $1,5 \%$ & \\
\hline \multicolumn{9}{|c|}{ Consumo (kg/dia) } \\
\hline $\mathrm{MV}$ & $2,468 \mathrm{a}$ & $1,792 b$ & $1,898 b$ & $1,528 b$ & $1,673 b$ & $2,100 \mathrm{a}$ & $1,733 b$ & 15,27 \\
\hline MS & $0,667 \mathrm{a}$ & $0,467 \mathrm{c}$ & $0,516 b$ & $0,387 \mathrm{c}$ & $0,537 b$ & $0,701 \mathrm{a}$ & $0,574 b$ & 13,71 \\
\hline FDN & $0,357 \mathrm{a}$ & $0,264 b$ & $0,288 b$ & $0,226 b$ & $0,286 b$ & $0,403 \mathrm{a}$ & $0,281 b$ & 15,99 \\
\hline FDA & $0,151 \mathrm{a}$ & $0,116 b$ & $0,121 b$ & $0,079 \mathrm{c}$ & $0,115 b$ & $0,121 b$ & $0,084 \mathrm{c}$ & 15,86 \\
\hline HEM & $0,206 b$ & $0,147 b$ & $0,166 b$ & $0,147 b$ & $0,170 \mathrm{~b}$ & $0,281 \mathrm{a}$ & $0,197 b$ & 17,89 \\
\hline PB & $0,023 a$ & $0,015 b$ & $0,017 \mathrm{~b}$ & $0,017 \mathrm{~b}$ & $0,013 \mathrm{~b}$ & $0,019 \mathrm{a}$ & $0,013 b$ & 16,06 \\
\hline \multicolumn{9}{|c|}{ Consumo $(\% \mathrm{PV})$} \\
\hline MV & $10,38 \mathrm{a}$ & $8,03 \mathrm{~b}$ & $8,69 b$ & $7,22 b$ & $7,41 b$ & $8,81 \mathrm{~b}$ & $8,05 \mathrm{~b}$ & 12,13 \\
\hline MS & $2,81 \mathrm{a}$ & $2,10 \mathrm{c}$ & $2,36 b$ & $1,82 \mathrm{c}$ & $2,39 b$ & $2,94 a$ & $2,67 \mathrm{a}$ & 11,58 \\
\hline FDN & $1,50 \mathrm{a}$ & $1,18 \mathrm{~b}$ & $1,31 b$ & $1,07 \mathrm{~b}$ & $1,27 b$ & $1,69 \mathrm{a}$ & $1,30 \mathrm{~b}$ & 12,59 \\
\hline FDA & $0,63 a$ & $0,52 \mathrm{a}$ & $0,55 \mathrm{a}$ & $0,37 b$ & $0,51 \mathrm{a}$ & $0,51 \mathrm{a}$ & $0,39 b$ & 13,95 \\
\hline HEM & $0,86 b$ & $0,66 c$ & $0,75 \mathrm{c}$ & $0,69 c$ & $0,76 \mathrm{c}$ & $1,18 \mathrm{a}$ & $0,91 b$ & 14,29 \\
\hline PB & $0,10 \mathrm{a}$ & $0,06 \mathrm{c}$ & $0,08 \mathrm{~b}$ & $0,08 \mathrm{~b}$ & $0,06 \mathrm{c}$ & $0,08 \mathrm{~b}$ & $0,06 \mathrm{c}$ & 13,56 \\
\hline \multicolumn{9}{|c|}{ Consumo $\left(\mathrm{g} / \mathrm{kg} \mathrm{PV} \mathrm{P}^{0,75}\right)$} \\
\hline MV & $229 a$ & $174 \mathrm{~b}$ & $187 \mathrm{~b}$ & $154 b$ & $161 b$ & $194 b$ & $173 b$ & 12,04 \\
\hline MS & $62 a$ & $45 c$ & $50 \mathrm{~b}$ & $39 c$ & $52 b$ & $64 a$ & $57 \mathrm{a}$ & 11,17 \\
\hline FDN & $33 a$ & $25 \mathrm{~b}$ & $28 \mathrm{~b}$ & $22 b$ & $27 \mathrm{~b}$ & $37 a$ & $28 b$ & 12,66 \\
\hline FDA & $14 \mathrm{a}$ & $11 \mathrm{~b}$ & $12 b$ & $7 \mathrm{c}$ & $11 \mathrm{~b}$ & $11 \mathrm{~b}$ & $8 \mathrm{c}$ & 13,61 \\
\hline HEM & $19 b$ & $14 \mathrm{c}$ & $16 \mathrm{c}$ & $14 c$ & $16 c$ & $26 a$ & $19 b$ & 14,43 \\
\hline PB & $2,19 a$ & $1,49 \mathrm{c}$ & $1,76 \mathrm{~b}$ & $1,74 b$ & $1,32 \mathrm{c}$ & $1,82 \mathrm{~b}$ & $1,34 \mathrm{c}$ & 13,82 \\
\hline
\end{tabular}

${ }^{\mathrm{T}} \mathrm{MV}$ = matéria verde; $\mathrm{MS}$ = matéria seca; FDN = fibra em detergente neutro; FDA = fibra em detergente ácido; HEM $=$ hemicelulose $\mathrm{PB}=$ proteína bruta; $\mathrm{PV}=$ peso vivo; $\mathrm{PV}^{0,75}=$ unidade de tamanho metabólico.

Médias seguidas de letras distintas na linha diferem entre si pelo teste de Scott-Knott a 5\% de significância.

Quando expresso o consumo em \% do PV e do peso metabólico, verificou-se maior consumo de MS para silagens tratadas com $0,5 \%$ de $\mathrm{NaCl}$, 1,0 e $1,5 \%$ de $\mathrm{CaO}$. Segundo Huhtanen et al. (2002), a utilização de aditivos é feita com o intuito de assegurar uma boa fermentação e minimizar as perdas durante a ensilagem, porém as alterações decorrentes do processo fermentativo influenciam o consumo. Balieiro Neto et al. (2009) avaliaram o consumo de MS por ovinos Ile de France e reportaram consumo de 0,657 (1,60\% do PV) e $0,720 \mathrm{~kg}(1,61 \%$ do PV) para dietas à base de cana-de-açúcar in natura e silagem tratada com $0,5 \%$ de óxido de cálcio, respectivamente.

Quando analisado somente o consumo de silagens tratadas com $\mathrm{NaCl}$, houve menor consumo de MS pelos animais devido às maiores doses (1,0 e 2,0\%), o que pode estar associado ao teor de sódio $\left(\mathrm{Na}^{+}\right)$, pois este exerce importante função reguladora no consumo. Carter e Grovum (1990) relataram decréscimo no consumo de 3,49g de $\mathrm{MS}$ do alimento/g de $\mathrm{NaCl}$ adicionado ao retículo-rúmen, quando a ingestão foi mensurada nos primeiros 10 minutos após adição de $2,37 \mathrm{~g}$ a $50 \mathrm{~g}$ de $\mathrm{NaCl}$ no retículo-rúmen de ovinos.

Registrou-se maior consumo de FDN $(\mathrm{P}<0,05)$ nas dietas compostas por silagens tratadas com $0,5 \%$ de $\mathrm{NaCl}$ e $1,0 \%$ de $\mathrm{CaO}$, independentemente da maneira como foi expresso, o que está de acordo com a ingestão de MS. Conforme descrito por Huhtanen et al. (2002), os aditivos utilizados na ensilagem da cana-de-açúcar podem ter proporcionado diferenças significativas quanto à FDN digestível, em decorrência de diferenças em hidrólise parcial de componentes da parede celular, proporcionando maior consumo pelo aumento da digestibilidade da FDN. O efeito dos produtos alcalinos normalmente ocorre pela solubilização parcial da hemicelulose e pela expansão da celulose, o que facilita o ataque dos microrganismos do rúmen à parede celular (Jackson, 1977).

De acordo com Schmidt et al. (2007), a FDN é a principal fração alimentar que exerce limitação 
sobre o consumo das dietas, pois, segundo Allen (1997), a ingestão de MS de forragens por ruminantes é limitada pela distensão resultante do fluxo de digesta pelo trato gastrintestinal, o que está correlacionado negativamente com o teor de FDN na dieta.

Os animais consumiram maior quantidade de FDA (kg/dia e $\mathrm{g} / \mathrm{kg} \mathrm{PV}^{0,75}$ ) quando alimentados com silagem tratada com $0,5 \%$ de $\mathrm{NaCl}(\mathrm{P}<0,05)$ (Tab. 3). Como descrito para o consumo de FDN, esse resultado está correlacionado com o maior consumo de MS verificado nesse tratamento. Entretanto, para a variável hemicelulose, notou-se maior consumo $(\mathrm{P}<0,05)$ em virtude da adição de 1,0\% de $\mathrm{CaO}$ à silagem de cana-de-açúcar. Esse resultado reflete a ação alcalinizante do óxido de cálcio, que proporciona o intumescimento alcalino da celulose (Van Soest, 1994), o que geralmente resulta no aumento da digestibilidade dessa fração, implicando maior consumo pelos animais.
Houve maior consumo de $\mathrm{PB}(\mathrm{P}<0,05)$ com a adição de $1,0 \%$ de $\mathrm{CaO}(\mathrm{kg} / \mathrm{dia})$ e $0,5 \%$ de $\mathrm{NaCl}$ ( $\mathrm{kg} /$ dia, \% PV e g/kg $\left.\mathrm{PV}^{0,75}\right)$ às silagens de cana-de-açúcar, resultado que reflete o consumo de MS pelos ovinos. Entretanto, o consumo observado em todos os tratamentos está abaixo dos relatados na literatura, o que se deve ao baixo teor de PB das dietas.

Registrou-se maior consumo de NDT e ED $(\mathrm{P}<0,05)$ para os animais alimentados com dietas à base de silagens de cana-de-açúcar tratadas com $0,5 \%$ de $\mathrm{NaCl}, 1,0$ e $1,5 \%$ de $\mathrm{CaO}(\mathrm{kg} / \mathrm{dia}$, \% PV e g/kg $\mathrm{PV}^{0,75}$ ), o que está associado ao maior consumo de MS verificado nesses tratamentos, exceto para a silagem tratada com $1,5 \%$ de $\mathrm{CaO}$. Para este tratamento, possivelmente houve maior digestibilidade aparente da MS, o que resulta em maior consumo, como descrito por Andrade et al. (2001). Segundo Restle et al. (2000), o maior consumo de MS associado à alta concentração energética das dietas implica aumento no consumo de ED.

Tabela 4. Consumo de energia por ovinos alimentados com dietas à base de silagens de cana-de-açúcar tratadas quimicamente

\begin{tabular}{|c|c|c|c|c|c|c|c|c|}
\hline \multirow{2}{*}{ Item $^{1}$} & \multicolumn{3}{|c|}{$\mathrm{NaCl}$} & \multirow{2}{*}{ Controle } & \multicolumn{3}{|c|}{$\mathrm{CaO}$} & \multirow{2}{*}{$\mathrm{CV}(\%)$} \\
\hline & $0,5 \%$ & $1,0 \%$ & $2,0 \%$ & & $0,5 \%$ & $1,0 \%$ & $1,5 \%$ & \\
\hline \multicolumn{9}{|c|}{ Consumo diário } \\
\hline NDT (kg/dia) & $0,480 \mathrm{a}$ & $0,329 b$ & $0,368 \mathrm{~b}$ & $0,284 b$ & $0,391 \mathrm{~b}$ & $0,530 \mathrm{a}$ & $0,445 \mathrm{a}$ & 13,64 \\
\hline ED (Mcal/dia) & $0,021 \mathrm{a}$ & $0,014 b$ & $0,016 b$ & $0,012 b$ & $0,017 \mathrm{~b}$ & $0,023 a$ & $0,019 \mathrm{a}$ & 13,64 \\
\hline EM (Mcal/dia) & $0,017 \mathrm{a}$ & $0,011 b$ & $0,013 b$ & $0,010 \mathrm{~b}$ & $0,014 b$ & $0,019 a$ & $0,016 \mathrm{a}$ & 13,64 \\
\hline NDT (\% PV) & $2,02 \mathrm{a}$ & $1,48 \mathrm{c}$ & $1,68 b$ & $1,34 \mathrm{c}$ & $1,74 \mathrm{~b}$ & $2,22 \mathrm{a}$ & $2,07 \mathrm{a}$ & 11,50 \\
\hline $\mathrm{ED}(\% \mathrm{PV})$ & $0,08 \mathrm{a}$ & $0,06 \mathrm{c}$ & $0,07 b$ & $0,06 \mathrm{c}$ & $0,07 b$ & $0,09 a$ & $0,09 \mathrm{a}$ & 13,03 \\
\hline $\mathrm{EM}(\% \mathrm{PV})$ & $0,07 \mathrm{a}$ & $0,05 b$ & $0,06 b$ & $0,04 \mathrm{~b}$ & $0,06 \mathrm{~b}$ & $0,07 \mathrm{a}$ & $0,07 \mathrm{a}$ & 13,15 \\
\hline NDT $\left(\mathrm{g} / \mathrm{kg} \mathrm{PV}^{0,75}\right)$ & $44 \mathrm{a}$ & $32 \mathrm{c}$ & $36 b$ & $28 \mathrm{c}$ & $37 b$ & $49 a$ & $44 \mathrm{a}$ & 11,09 \\
\hline $\mathrm{ED}\left(\mathrm{g} / \mathrm{kg} \mathrm{PV}^{0,75}\right)$ & $1,97 \mathrm{a}$ & $1,41 \mathrm{c}$ & $1,60 \mathrm{~b}$ & $1,27 \mathrm{c}$ & $1,67 b$ & $2,17 \mathrm{a}$ & $1,96 a$ & 11,09 \\
\hline $\operatorname{EM}\left(\mathrm{g} / \mathrm{kg} \mathrm{PV}^{0,75}\right)$ & $1,61 \mathrm{a}$ & $1,16 \mathrm{c}$ & $1,31 \mathrm{~b}$ & $1,04 \mathrm{c}$ & $1,37 \mathrm{~b}$ & $1,77 \mathrm{a}$ & $1,61 \mathrm{a}$ & 11,11 \\
\hline
\end{tabular}

${ }^{1} \mathrm{NDT}$ = nutrientes digestíveis totais; $\mathrm{ED}=$ energia digestível; $\mathrm{EM}=$ energia metabolizável; $\mathrm{PV}=$ peso vivo; $\mathrm{PV}^{0,75}=$ unidade de tamanho metabólico.

Médias seguidas de letras distintas na linha diferem entre si pelo teste de Scott-Knott a 5\% de significância.

Os valores encontrados neste trabalho (Tab. 4) são mais altos que os verificados por Lopes et al. (2007), que reportaram consumo de $20,35 \mathrm{~g} / \mathrm{kg}$ $\mathrm{PV}^{0,75}$, de NDT por ovelhas Santa Inês (peso médio de $36,5 \mathrm{~kg}$ ), quando alimentadas com dietas à base de silagem de cana-de-açúcar controle (sem utilização de aditivos).

Com relação ao consumo de EM, verificou-se maior consumo $(\mathrm{P}<0,05)$ para os animais que receberam os tratamentos contendo $0,5 \%$ de $\mathrm{NaCl}, 1,0$ e $1,5 \%$ de $\mathrm{CaO}(\mathrm{kg} / \mathrm{dia}, \%$ PV e g/kg $\mathrm{PV}^{0,75}$, o que está de acordo com os resultados verificados para as variáveis NDT e ED. Não houve efeito $(\mathrm{P}>0,05)$ das dietas sobre o GPMD, contudo notou-se maior ganho de peso médio total $(\mathrm{GPMT})(\mathrm{P}<0,05)$ para animais alimentados com dietas à base de silagens de cana-de-açúcar tratadas com $0,5 \%$ de $\mathrm{NaCl}$ e 1,0 e $1,5 \%$ de $\mathrm{CaO}$ (Tab. 5). 
Consumo e desempenho de ovinos...

Tabela 5. Desempenho de ovinos alimentados com dietas à base de silagens de cana-de-açúcar tratadas quimicamente

\begin{tabular}{|c|c|c|c|c|c|c|c|c|}
\hline \multirow{2}{*}{ Item $^{1}$} & \multicolumn{3}{|c|}{$\mathrm{NaCl}$} & \multirow{2}{*}{ Controle } & \multicolumn{3}{|c|}{$\mathrm{CaO}$} & \multirow{2}{*}{ CV (\%) } \\
\hline & $0,5 \%$ & $1,0 \%$ & $2,0 \%$ & & $0,5 \%$ & $1,0 \%$ & $1,5 \%$ & \\
\hline PV inicial & 23,700 & 22,275 & 22,175 & 21,100 & 22,525 & 23,925 & 21,500 & 10,88 \\
\hline PV final & 24,975 & 22,175 & 22,900 & 20,875 & 22,100 & 25,950 & 23,450 & 11,16 \\
\hline GPMD $(\mathrm{g})$ & 73 & -7 & 51 & -16 & -30 & 144 & 137 & 180,95 \\
\hline GPMT (kg) & $1,275 \mathrm{a}$ & $-0,100 b$ & $0,725 b$ & $-0,255 b$ & $-0,425 b$ & $2,025 \mathrm{a}$ & $1,950 \mathrm{a}$ & 169,78 \\
\hline
\end{tabular}

${ }^{1} \mathrm{PV}=$ peso vivo; GPMD = ganho de peso médio diário; GPMT = ganho de peso médio total.

Médias seguidas de letras distintas na linha diferem entre si pelo teste de Scott-Knott a 5\% de significância.

Os maiores ganhos de peso total verificados nos animais alimentados com silagens tratadas com $0,5 \%$ de $\mathrm{NaCl}$ e $1,0 \%$ de $\mathrm{CaO}$ estão de acordo com os maiores consumos de MS e energia provenientes da dieta, o que invariavelmente resulta em melhor desempenho animal. Entretanto, o maior ganho de peso verificado também nos animais tratados com silagem de cana-de-açúcar contendo $1,5 \%$ de $\mathrm{CaO}$ parece estar mais relacionado à eficiência na utilização desse alimento, pois, embora o consumo de MS tenha sido inferior aos tratamentos citados acima, o consumo de energia foi semelhante, sugerindo maior eficiência na degradação do alimento pela população microbiana presente no rúmen.

\section{CONCLUSÕES}

A adição de $0,5 \%$ de cloreto de sódio e $1,0 \%$ de óxido de cálcio à silagem de cana-de-açúcar resulta em aumento no consumo e melhora no desempenho de ovinos. Há recusa de silagens pelos animais quando tratadas com altas concentrações de cloreto de sódio, implicando menor consumo de matéria seca.

\section{AGRADECIMENTOS}

À Fundação de Amparo à Pesquisa do Estado de Minas Gerais (Fapemig), pela bolsa de iniciação científica concedida ao primeiro autor.

\section{REFERÊNCIAS}

ALLEN, M.S. Relationship between fermentation acid production in the rumen and the requirement for physically effective fiber. J. Dairy Sci., v.80, p.14471462, 1997.

AMARAL, R.C.; PIRES, A.V.; SUSIN, I. et al. Canade-açúcar ensilada com ou sem aditivos químicos: fermentação e composição química. Rev. Bras. Zootec., v.38, p.1413-1421, 2009.
ANDRADE, J.B.; FERRARI JÚNIOR, E.; BRAUN, G. Valor nutritivo da silagem de cana-de-açúcar tratada com ureia e acrescida de rolão-de-milho. Pesq. Agropec. Bras., v.36, p.1169-1174, 2001.

BALIEIRO NETO, G.; SIQUEIRA, G.R.; REIS, R.A. et al. Óxido de cálcio como aditivo na ensilagem de cana-de-açúcar. Rev. Bras. Zootec., v.36, p.1231-1239, 2007.

BALIEIRO NETO, G.; FERRARI JÚNIOR, E.; NOGUEIRA, J.R. et al. Perdas fermentativas, composição química, estabilidade aeróbia e digestibilidade aparente de silagem de cana-de-açúcar com aditivos químico e microbiano. Pesq. Agropec. Bras., v.44, p.621-630, 2009.

BOLZAN, I.T.; SANCHEZ, L.M.B.; CARVALHO, P.A. et al. Consumo e digestibilidade em ovinos alimentados com dietas contendo grão de milho moído, inteiro ou tratado com ureia, com três níveis de concentrado. Cienc. Rural, v.37, p.229-234, 2007.

CAPPELLE, E.R.; VALADARES FILHO, S.C.; SILVA, J.F.C. et al. Estimativas no valor energético a partir de características químicas e bromatológicas dos alimentos. Rev. Bras. Zootec., v.30, p.1837-1856, 2001.

CARTER, R.R.; GROVUM, W.L. Factors affecting the voluntary intake of food by sheep. 5. The inhibitory effect of hypertonicity in the rumen. $\mathrm{Br} . J$. Nutr., v.64, p.285-299, 1990.

FERREIRA, D.F. SISVAR: um programa para análises e ensino de estatística. Rev. Cient. Symposium, v.6, p.36-41, 2008.

FREITAS, A.W.P.; PEREIRA, J.C.; ROCHA, F.C. $e t$ $a l$. Avaliação da qualidade nutricional da silagem de cana-de-açúcar com aditivos microbianos e enriquecida com resíduo da colheita de soja. Rev. Bras. Zootec., v.35, p.38-47, 2006.

GAVA, A.J. Princípios de tecnologia de alimentos. São Paulo: Nobel, 1984. 284p.

HUHTANEN, P.; KHALILI, H.; NOUSIAINEN, J.I. et al. Prediction of the relative intake potential of grass silage by dairy cows. Livest. Prod. Sci., v.72, p.111130, 2002. 
JACKSON, M.G. Review article: the alkali treatment of straws. Anim. Feed Sci. Technol., v.2, p.105-130, 1977.

LOPES, J.; EVANGELISTA, A.R. Características bromatológicas, fermentativas e população de leveduras de silagens de cana-de-açúcar acrescidas de ureia e aditivos absorventes de umidade. Rev. Bras. Zootec., v.39, p.984-991, 2010.

LOPES, J.; EVANGELISTA, A.R.; ROCHA, G.P. Valor nutricional de cana-de-açúcar acrescida de ureia e aditivos absorventes de umidade. Rev. Bras. Zootec., v.36, p.1155-1161, 2007.

MAGALHÃES, A.L.R.; CAMPOS, J.M.S.; VALADARES FILHO, S.C. et al. Cana-de-açúcar em substituição à silagem de milho em dietas para vacas em lactação: desempenho e viabilidade econômica. Rev. Bras. Zootec., v.33, p.1292-1302, 2004.

NUSSIO, L.G.; SCHMIDT, P. Silagens de cana-de-açúcar para bovinos leiteiros: aspectos agronômicos e nutricionais. In: SIMPÓSIO SOBRE BOVINOCULTURA LEITEIRA, 5., 2005, Piracicaba. Visão técnica e econômica da produção leiteira. Anais... Piracicaba: Fundação de Estudos Agrários Luiz de Queiroz, 2005. p.193-218.

NUSSIO, L.G.; SUSIN, I.; MENDES, C.Q. et al. Estratégias para garantir eficiência na utilização de cana-de-açúcar para ruminantes. Tecnol. Cienc. Agropec., v.3, p.27-33, 2009.

RESTLE, J.; ALVES FILHO, D.C.; BRONDANI, I.L. et al. Palha de Soja (Glycine max) como substituto parcial da silagem de sorgo forrageiro (Sorghum bicolor (L.) Moench) na alimentação de terneiros de corte confinados. Cienc. Rural, v.30, p.319-324, 2000.
REZENDE, A.V.; RABELO, C.H.S.; RABELO, F.H.S. et al. Perdas fermentativas e estabilidade aeróbia de silagens de cana-de-açúcar tratadas com cal virgem e cloreto de sódio. Rev. Bras. Zootec., v.40, p.739-746, 2011.

RODRIGUES, R.C. Avaliação químico-bromatológica de alimentos produzidos em terras baixas para nutrição animal. Empresa Brasileira de Pesquisa Agropecuária -EMBRAPA, Pelotas, 2009. 31p.

SANTOS, M.C.; NUSSIO, L.G.; MOURÃO, G.B. et $a l$. Influência da utilização de aditivos químicos no perfil da fermentação, no valor nutritivo e nas perdas de silagens de cana-de-açúcar. Rev. Bras. Zootec., v.37, p.1555-1563, 2008.

SCHMIDT, P.; MARI, L.J.; NUSSIO, L.G. et al. Aditivos químicos e biológicos na ensilagem de canade-açúcar. 1. Composição química das silagens, ingestão, digestibilidade e comportamento ingestivo. Rev. Bras. Zootec., v.36, p.1666-1675, 2007.

SILVA, D.J.; QUEIROZ, A.C. Análise de alimentos: Métodos Químicos e Biológicos. Universidade Federal de Viçosa: Viçosa, 2002. 235p.

TORRES, L.B.; FERREIRA, M.A.; VÉRAS, A.S.C. et al. Níveis de bagaço de cana e ureia como substituto ao farelo de soja em dietas para bovinos leiteiros em crescimento. Rev. Bras. Zootec., v.32, p.760-767, 2003.

VAN SOEST, P.J. Nutritional ecology of the ruminant. 2.ed. Cornell University Press. Constock Publish, 1994. 476p.

WOOLFORD, M.K. The problem of silage effluent. Herb. Abs., v.48, p.397-403, 1978. 